\title{
Optimized design and experiments of a rotary-extensive-type flowerpot seedling transplanting mechanism
}

\author{
Daqing Yin ${ }^{1}$, Jiazhao Wang ${ }^{1}$, Shuo Zhang ${ }^{2}$, Nuoyi Zhang ${ }^{1}$, Maile Zhou ${ }^{1 *}$ \\ (1. College of Engineering, Northeast Agricultural University, Harbin 150030, China; \\ 2. MMI Planning \& Engineering Institute IX Co., Ltd., Changchun 130011, China)
}

\begin{abstract}
To realize the mechanization of flowerpot seedling transplanting, a creative mechanism to transplant flowerpot seedlings was designed. The mechanism is based on noncircular gear in combination with a transplanting arm equipped with an extensive seedling pick-up device to transplant the flowerpot seedlings from the growing tray to the flowerpot, which in accordance with the transplanting agronomy requirements. The working principles of a theoretical model and kinematic characteristics of the transplanting mechanism were analyzed. The computer-aided analysis and optimization software based on Visual Basic 6.0 was developed and used to obtain a set of special trajectory and attitude parameters satisfying the transplanting operation requirements. The optimized parameters were used for virtual manufacturing and simulation testing of the transplanting mechanism. The virtual prototype testing results are consistent with the theoretical analysis, verifying the structural design validity and rationality. The high-speed photography was used in a bench test of the transplanting mechanism with "Salvia Splendens" pot seedlings as test samples. The trajectory and attitudes of the theoretical analysis, virtual test, and physical prototype test were essentially identical. The bench test results showed that the success rate was $91.67 \%$ for the seedling pick-up device penetrating into the root mass at $35 \mathrm{~mm}$, thus, the quality of the extracting seedling was satisfactory.
\end{abstract}

Keywords: transplanting mechanism, rotary-extensile type, pot seedlings, flowers

DOI: $10.25165 /$ j.ijabe.20191206.5188

Citation: Yin D Q, Wang J Z, Zhang S, Zhang N Y, Zhou M L. Optimization design and experiments of a rotary-extensile type flowerpot seedling transplanting mechanism. Int J Agric \& Biol Eng, 2019; 12(6): 45-50.

\section{Introduction}

With the acceleration of China's urbanization process, urban landscape construction gradually advances. Potted flower seedlings are often used for decoration and beautifying the surroundings and have a great market demand ${ }^{[1]}$. The transplanting method is that seedling production occurs on a growing tray, and then the flowerpot seedlings are transplanted from the tray to the flowerpot with a suitable growth status ${ }^{[2]}$.

Manual transplantation at a large commercial scale remains labor-intensive, inefficient and expensive. To realize the mechanization of a potted flower plant, the Netherlands, the United States and other countries have applied mechatronics technology to increase the efficiency of flowerpot seedling transplantation by expanding the number of manipulators. However, the structure of the potted flower seedling transplanting mechanism with mechatronics technology is complicated, expensive, and not easy to localize ${ }^{[3-6]}$. As a recent development of flowerpot transplantation in China, many attempts have been made to improve the transplanting mechanism ${ }^{[7-10]}$. However, there are few studies regarding the transplanting mechanism for potted flowers.

Gao et al. ${ }^{[11]}$ designed a transplanting manipulator of potted

Received date: 2019-06-03 Accepted date: 2019-11-03

Biographies: Daqing Yin, PhD, Associate Professor, research interests: design and application of agricultural machinery, Email: 63900962@qq.com; Jiazhao Wang, Master candidate, research interests: transplanting equipment, Email: 15004655293@163.com; Shuo Zhang, Master candidate, research interests: transplanting equipment, Email: zhangshuo_jy@faw.com.cn; Nuoyi Zhang, Master candidate, research interests: transplanting, Email: zxrjing@126.com.

*Corresponding author: Maile Zhou, PhD, Lecturer, research interests: design and application of agricultural machinery. Email: zhoumaile@126.com. anthurium that grasped the stem of flower seedlings from both sides, which could provide sufficient grasping force. The gathering gripper was used to protect the leaves, and the steel needles were used to fix the flower seedlings to complete the transplanting task. Feng et al. ${ }^{[12]}$ reported that a key part of automatic transplanting for flower seedlings was developed based on the machine's vision technology. This flexible grasper was applied to hold the seedling root; after inserting the fingers into the soil, the ring-shaped spring drove the fingers to remove the seedling from the tray holes to the flowerpots. Zhou et al. ${ }^{[13]}$ designed an automatic transplanting mechanism for taking and planting of flower plug seedlings, including good seedling effect and poor seedling effect. To develop a high-efficiency and simple flowerpot transplanting mechanism is of great significance for liberating labor and realizing large-scale flowerpot transplantation.

The objective of this work was to develop a structurally simple and low-cost flowerpot seedling transplanting mechanism using the mechanical principle that is capable of satisfying flowerpot transplanting requirements, which solves the problem that the general rotary transplanting mechanism ${ }^{[14,15]}$ can only realize a "sharp-mouth-shaped" seedling pick-up trajectory, as it cannot meet other transplanting requirements. Its performance was evaluated by a series of tests, such as virtual, high-speed photography and bench tests. The results from the model were consistent with those from the bench test, verifying the validity and feasibility of the transplanting mechanism.

\section{Design requirements and working principles of the transplanting mechanism}

\subsection{Design requirements}

As shown in Figure 1, the mechanism should complete four 
continuous stages of seedling picking, transportation, planting and return in one cycle and meet the following design requirements:

(1) ABC seedling picking segment: in the process of seedling picking, the seedling needle was poked out to stick into the soil pot at the angle of fixation and the seedling was removed from the hole plate to complete the seedling picking action.

(2) CE Transferring section: take the seedling needle to hold the pot soil, under the rotation action of the transplanting arm, transport the pot seedling to the position where the pot seedling is located, and complete the Transferring process.

(3) ED planting section: the seedling needle was pulled back quickly, and the flower pot seedling was separated from the flowerpot. In this process, the flower pot seedling was not moved in the substrate of the flowerpot, and the seedling planting process was realized.

(4) DA return section: the mechanism returns to its original position and prepares to enter the next operation.

(5) Seedling clamping method: the stems of the flowerpot seedlings are much weaker from a test of their physical characteristics, and it will be very difficult for the plant to survive if the stems are damaged during transplantation. Therefore, the method of insertion into a base material from both sides of the stem using a seedling needle is adopted to avoid damage to the seedling stem and leaves during transplantation.

(6) Transmission mode: the characteristics of a transmission ratio of noncircular gear to obtain an "olecranon-shaped" transplanting trajectory are used.

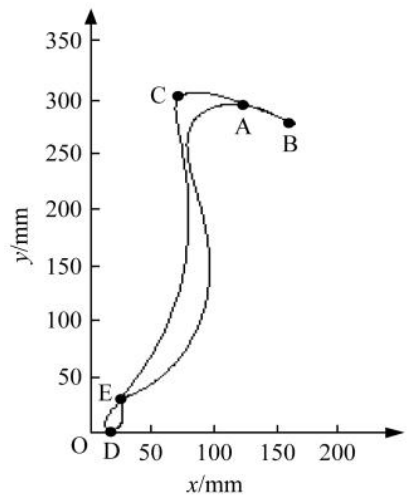

Figure 1 Trajectory of rotary-extensive-type flowerpot seedling transplanting mechanism

\subsection{Composition and working principles}

The transplanting system is mainly composed of a transplanting mechanism, seedling box and conveyor belt, as shown in Figure 2. The transplanting mechanism consists of a planetary gear train, transplanting arm and seedling pick-up device $^{[16]}$. The planetary gear train is composed of a sun gear, an intermediate gear, a planetary gear and a planet carrier. The transplanting arm includes a cam and fork. A seedling-pushing rod, a slide way, and a seedling needle form the seedling pick-up device. The sun gear is fixed to the frame, the transplanting arm and the planetary gear are fixed, and the end of the seedling pick-up device and the transplanting arm are fixed.

As shown in Figure 3, the transplanting arm completes the action of seedling picking and pushing. When the transplanting mechanism works, the planet carrier rotates counterclockwise, and the planetary gear drives the transplanting arm and the seedling pick-up device to rotate. When the seedling pick-up device moves to the seedling pick-up position, the cam drives the fork movement to push the seedling-pushing rod, thereby driving the seedling pick-up needle to move along the slide way. The seedling pick-up needle inserts into the tray at a fixed angle for seedling picking, as shown in Figure 4. Then, the seedling pick-up device moves to the planting position, the cam returns, and the seedling-pushing rod returns and drives the needle to retract; the flower seedling falls into the flowerpot, and the transplanting action is complete. The conveyor belt continuously rotates and transports the planted flowerpot to one end, and then it is removed until flower transplantation is complete. The transplanting mechanism rotates in a circle to complete a seedling transplanting process. The position of the flowerpot is determined by adjusting the speed at which the mechanism rotates and the conveyor belt to ensure that the flower seedlings can accurately fall into the flowerpot.

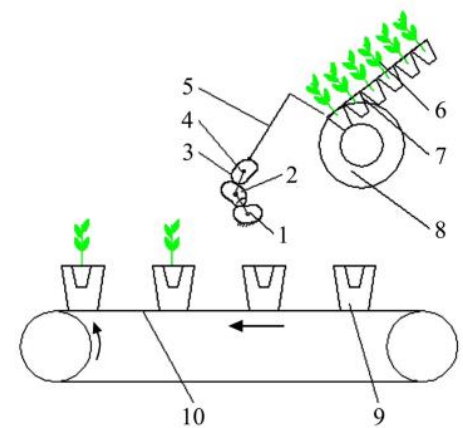

1. Sun gear 2. Intermediate gear 3. Planetary gear 4. Planet carrier 5. Transplanting arm 6. Seedling 7.Tray 8. Seedling box 9. Flowerpot 10. Conveyor belt

Figure 2 Schematic diagram of the flowerpot seedling transplanting mechanism

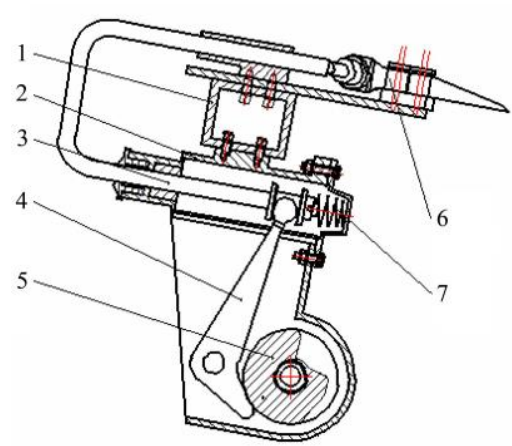

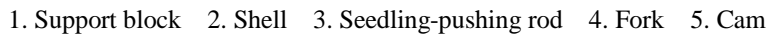
6. Seedling pick-up needle 7. Spring

Figure 3 Structural diagram of the transplanting arm

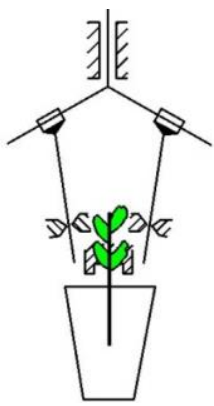

a. Before taking seedling

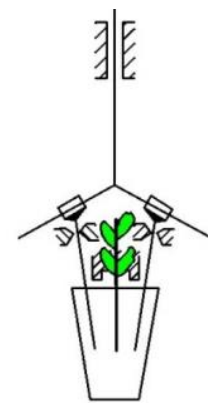

b. Status of taking seedling
Figure 4 Schematic diagram of seedling picking

\section{Establishment of the kinematic model of the transplanting mechanism}

\subsection{Establishment of the kinematic model}

The established Cartesian coordinate system $O_{1} X Y$ is presented in Figure 5. 


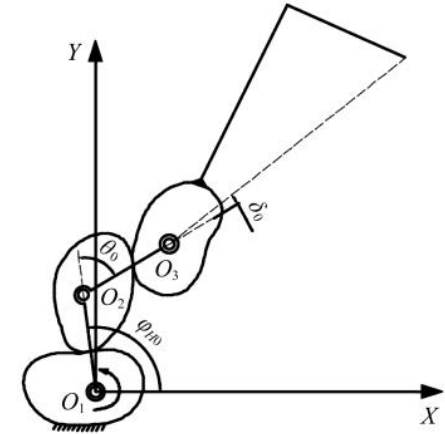

Figure 5 Schematic diagram of the transplanting mechanism

To facilitate the analysis of the kinematic model of the mechanism, the setting of counterclockwise is a positive direction, and clockwise is a negative direction. Since the end of the seedling pick-up device is fixed with the transplanting arm, the seedling pick-up device and the transplanting arm are regarded as one during the kinematic analysis; the change in the short side of the transplanting arm is a means for the expression of the extension and trajectory of the seedling pick-up needle. Equations of rotation angle and angular velocity of each gear in the transplanting mechanism are established. Displacement and velocity equations of the seedling pick-up needle are proposed.

\subsection{Analysis of the transplanting mechanism (angular) displacement}

During the transplanting mechanism working process, the planet carrier rotates counterclockwise, and the sun gear is fixed. When the planet carrier rotates counterclockwise by the angle $\varphi\left(^{\circ}\right)$, the angle of the gear $i$ relative to the planet carrier is expressed by $\beta_{i}(\varphi),\left(^{\circ}\right)$; the absolute angle of the gear $i$ relative to the frame is expressed by $\varphi_{i}(\varphi),\left(^{\circ}\right)$; and the distance from the gear $i$ axis to the engaging point is expressed by $r_{i}(x), \mathrm{mm}$; at the initial position, $\varphi_{H O}$ is the angle between the planet frame and the $\mathrm{x}$ axis, $\left({ }^{\circ}\right)$; the corner of a planet rack is expressed by $\theta_{0},\left(^{\circ}\right) ; \delta_{0}$ is the angle between the transplanting arm and the frame, $\left(^{\circ}\right) ; O_{i}$ is the rotation center of the gear $i$; $\left|O_{1} O_{2}\right|$ is the center distance between the sun gear and the intermediate gear; $\left|\mathrm{O}_{2} \mathrm{O}_{3}\right|$ is the center distance between the intermediate gear and the planetary gear; $\left|O_{3} D_{1}\right|$ is the distance between the planetary gear center and the tip point.

The absolute angle of the planet carrier relative to the frame is :

$$
\varphi_{H}(\varphi)=\varphi_{H 0}+\varphi
$$

The relative rotation angles of the sun gear is $\beta_{1}(\varphi),\left({ }^{\circ}\right)$; the absolute rotation angles of the sun gear is $\varphi_{1}(\varphi),\left(^{\circ}\right)$ :

$$
\left\{\begin{array}{l}
\beta_{1}(\varphi)=-\varphi \\
\varphi_{1}(\varphi)=\varphi_{H 0}
\end{array}\right.
$$

The relative rotation angles of the intermediate gear is $\beta_{2}(\varphi)$, $\left(^{\circ}\right)$; the absolute rotation angles of the intermediate gear is $\varphi_{2}(\varphi)$, $\left({ }^{\circ}\right)$ :

$$
\left\{\begin{array}{l}
\beta_{2}(\varphi)=\int_{0}^{-\varphi} \frac{r_{1}(x)}{\left|O_{1} O_{2}\right|-r_{1}(x)} \mathrm{d} x \\
\varphi_{2}(\varphi)=\varphi_{H}(\varphi)+\beta_{2}(\varphi)
\end{array}\right.
$$

The relative rotation angles of the planetary gear is $\beta_{3}(\varphi),\left(^{\circ}\right)$; the absolute rotation angles of the planetary gear is $\varphi_{3}(\varphi),\left(^{\circ}\right)$ :

$$
\left\{\begin{array}{l}
\beta_{3}(\varphi)=\int_{\theta_{0}}^{\beta_{2}(\varphi)+\theta_{0}} \frac{r_{2}(x)}{\left|O_{2} O_{3}\right|-r_{2}(x)} \mathrm{d} x \\
\varphi_{3}(\varphi)=\varphi_{H}(\varphi)+\theta_{0}-\varphi_{30}-\beta_{3}(\varphi)
\end{array}\right.
$$

where, $\varphi_{30}$ is the initial installation angle of the planetary gear caused by the slip angle of the planet carrier, $\left(^{\circ}\right)$ :

$$
\varphi_{30}=\int_{0}^{\theta_{0}} \frac{r_{2}(2 \pi-x)}{\left|O_{2} O_{3}\right|-r_{2}(2 \pi-x)} \mathrm{d} x
$$

The rotation center coordinates of the intermediate gear is $\left(x_{2}, y_{2}\right), \mathrm{mm}$; The rotation center coordinates of the planetary gear is $\left(x_{3}, y_{3}\right), \mathrm{mm}$.

$$
\begin{gathered}
\left\{\begin{array}{l}
x_{2}(\varphi)=\left|O_{1} O_{2}\right| \cdot \cos \left(\varphi_{H 0}+\varphi\right) \\
y_{2}(\varphi)=\left|O_{1} O_{2}\right| \cdot \sin \left(\varphi_{H 0}+\varphi\right)
\end{array}\right. \\
\left\{\begin{array}{l}
x_{3}(\varphi)=x_{2}(\varphi)+\left|O_{2} O_{3}\right| \cdot \cos \left(\varphi_{H 0}+\varphi+\theta_{0}\right) \\
y_{3}(\varphi)=y_{2}(\varphi)+\left|O_{2} O_{3}\right| \cdot \sin \left(\varphi_{H 0}+\varphi+\theta_{0}\right)
\end{array}\right.
\end{gathered}
$$

Through the center coordinates of the planetary gear (gear 3 ), the absolute coordinates of the tip point of the seedling pick-up needle relative to the frame can be determined as $\left(x_{D_{1}}, y_{D_{1}}\right), \mathrm{mm}$ :

$$
\left\{\begin{array}{l}
x_{D_{1}}(\varphi)=x_{3}(\varphi)+\left|O_{3} D_{1}\right| \cdot \cos \left[\varphi_{H 0}+\theta_{0}+\delta_{0}+\varphi-\beta_{3}(\varphi)\right] \\
y_{D_{1}}(\varphi)=y_{3}(\varphi)+\left|O_{3} D_{1}\right| \cdot \sin \left[\varphi_{H 0}+\theta_{0}+\delta_{0}+\varphi-\beta_{3}(\varphi)\right]
\end{array}\right.
$$

When the gears are mutually engaged, the center distance remains the same.

\section{Development of the auxiliary optimization and design platform}

\subsection{Determination of optimization objectives}

The ideal trajectory of the seedling pick-up section requires that when the mechanism moves to a position near the tray, the seedling pick-up needle always remains perpendicular to the tray. At this time, the extension of the pick-up needle can ensure that the needle is inserted into the base material at a fixed angle. To reduce the damage to the root soil, the trajectory of the seedling picking should be as near as possible to the needle insertion trajectory. To successfully pick up the seedlings, the length of the approximate straight line (that is, the depth of the picking seedlings) should be longer than $30 \mathrm{~mm}$. The results showed that when the depth of the seedling picking was less than $30 \mathrm{~mm}$, the effect of the seedling picking was not satisfactory. The depth of seedling pick-up should be less than $40 \mathrm{~mm}$ to avoid damage to the root soil.

In addition to the trajectory requirements of the seedling pick-up section, the following objective requirements were considered:

(1) The transplanting arm components do not interfere with the seedling box when working.

(2) To ensure seedling verticality, the angle difference between the seedling pushing angle and seedling picking angle should closely approximate the inclination of the seedling box.

(3) To avoid a collision between the gearbox and the flowerpot, the distance between the gearbox and flowerpot should be longer than $15 \mathrm{~mm}$.

(4) To ensure the strength of the noncircular gear, the gear modulus needs to be greater than $2.5 \mathrm{~mm}$.

Combining kinematic analysis and institutional optimization goals, the visual optimization and design software are written. The software interface is shown in Figure 6.

\subsection{Analysis and determination of the trajectory}

As shown in Figure 5, the trajectory is the mark of the tip point of the seedling pick-up needle when the seedling pick-up device is not extended. However, because of the seedling pick-up needle extending and retracting, the length of the short side of the transplanting arm changes, causing the trajectory to change. To obtain the final trajectory of the tip point of the seedling pick-up needle, we use the function of the Application Software to preserve the track to analyze the trajectory. 

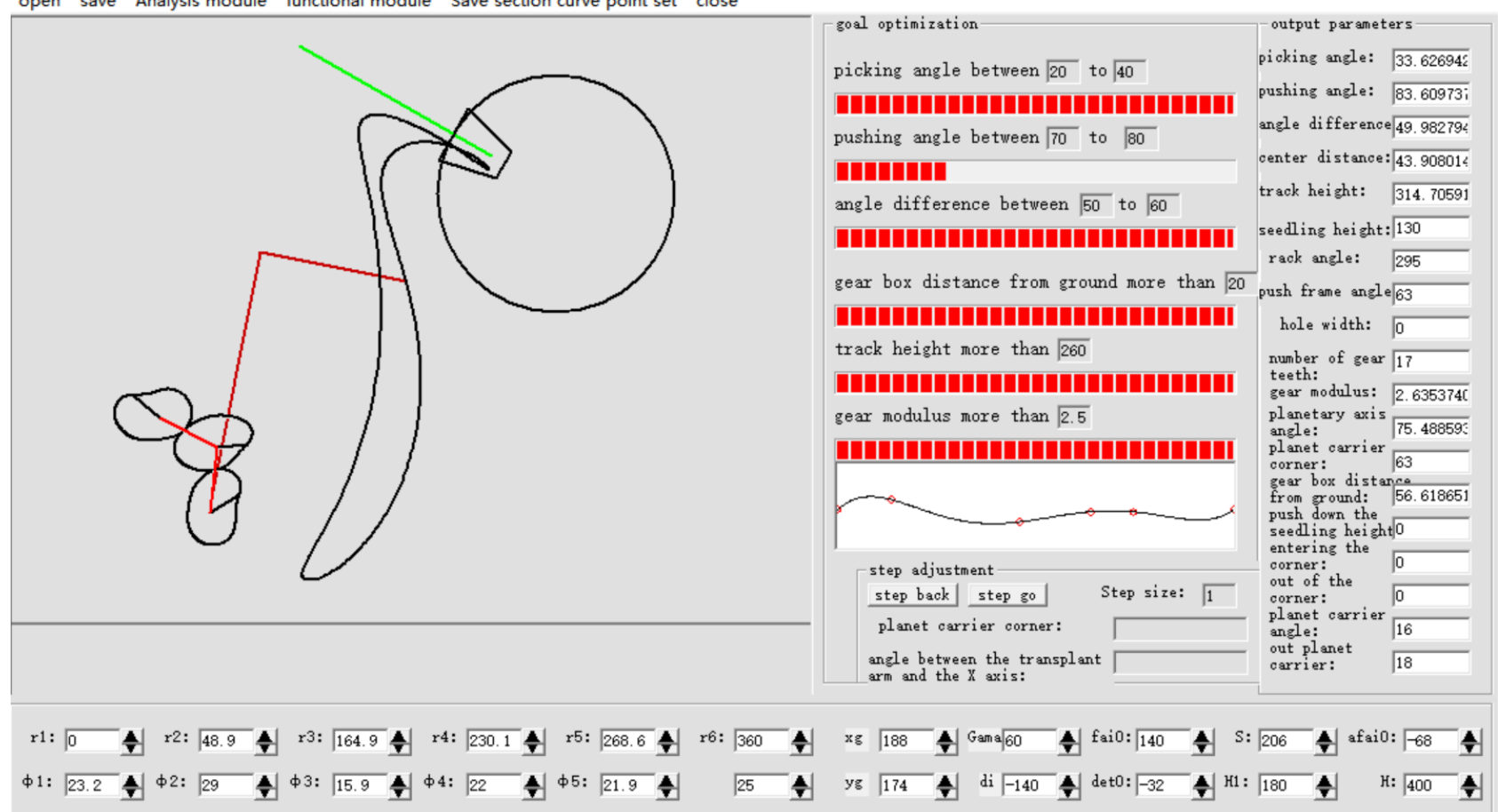

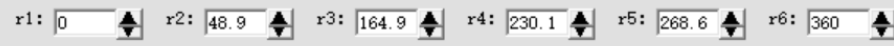

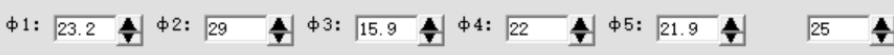

Figure 6 Optimization and design software of the transplanting mechanism

The planet carrier rotates counterclockwise. During the seedling pick-up stage, the trajectory of the seedling pick-up needle is as shown in Figure 7a. When the needle tip point is moving toward point $A$, the needle extends, and the $A B$ segment is the route of the seedling pick-up needle in the tray. While the tip point of the seedling pick-up needle is moving toward B, the length of the short side of the transplanting arm increases; the trajectory of preservation is shown in Figure $7 b$. When the tip point of the seedling pick-up needle moves to point $C$, the mechanism completes the seedling pick-up action. The planet carrier rotates, and the seedlings are transferred to the top of the flowerpot. When the tip point of the seedling pick-up needle is moving to point $\mathrm{E}$, the seedling pick-up needle is retracting, and the plant falls into the flowerpot to complete the transplanting action. After the transplanting operation is completed, the length of the short side of the transplanting arm is reduced, and the trajectory is restored to the EA section as shown in Figure 7a. The two parts of the trajectory before and after probing were combined to obtain the final trajectory of the transplantation, as shown in Figure $7 \mathrm{~b}$.

By comparing the trajectory before probing and the trajectory after probing, it is found that the distance between the mechanism and the seedling box is reduced after the seedling pick-up needle is extended; thus, the trajectory coincides after the mechanism is retracted (point $E$ ). When optimizing the parameters, it is necessary to ensure that the mechanism does not interfere with the seedling box at any time. The height of the trajectory increases after the seedling pick-up needle is extended, and when the mechanism moves to the lowest point, a 'loop-shaped' trajectory is formed in the contraction of the extensile mechanism with the rotation of the planet carrier. Previous experimental results show that the seedling pick-up effect is better when the seedling pick-up depth is $32-40 \mathrm{~mm}$; however, during the process of optimizing the trajectory, when the short side length of the transplanting arm increases to the $32-40 \mathrm{~mm}$, the trajectory only changes the length of the $A B$ segment. The $A B$ segment trajectory meets the work requirements; thus, it is impossible to determine the optimal seedling pick-up depth ( $A B$ segment length). During the optimization process, the depth of the seedling pick-up is tentatively set to a limit of $40 \mathrm{~mm}$, ensuring the seedling pick-up needle and the seedling box are not interfered with at the limit depth of $40 \mathrm{~mm}$; the optimal seedling depth is determined in the bench tests.

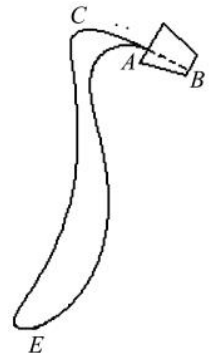

a. The trajectory before probing

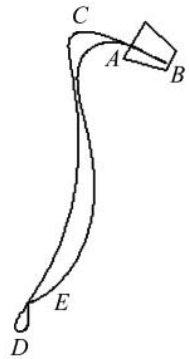

b. The trajectory after probing
Figure 7 Diagram of trajectory analysis

Through a human-computer interaction optimization method ${ }^{[17]}$, a set of institutional parameters that satisfy each optimization goal is obtained. The planet carrier initial angle $\varphi_{H 0}=140^{\circ}$ and the transplanting arm initial installation angle $\delta_{0}=-32^{\circ}$. The distance from the rotary center of the planetary gear to the seedling-pushing $\operatorname{rod} S=156 \mathrm{~mm}$, the length of the long side of the transplanting arm $H 1=149 \mathrm{~mm}$, and the corner of the planet carrier $\theta_{0}=-68^{\circ}$.

\section{Experimental research}

\subsection{Virtual model machine text}

According to the optimized parameters, the structural design, three-dimensional modeling and assembly of the transplanting mechanism are conducted. The three-dimensional model is imported into the ADAMS software to perform a virtual prototype testing of the transplanting mechanism. In the virtual prototype testing, the simulation curve of the trajectory of the tip point of the seedling pick-up needle can be measured, as shown in Figure 8. This trajectory is basically consistent with the trajectory of the 
theoretical optimization trajectory, which verifies the correctness of theoretical analysis and virtual experiment and ensures the practical feasibility of the mechanism.

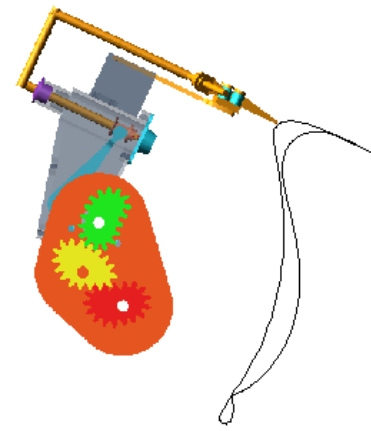

Figure 8 Experimental trajectory of the virtual prototype

\subsection{High-speed photography test}

To ensure that the trajectory of the transplanting mechanism in the actual work is consistent with the trajectory of the theoretical optimization and the trajectory in the virtual prototype test, a high-speed photography test is carried out for the transplanting mechanism. The relative trajectory of the tip point of the seedling pick-up needle is obtained and analyzed.

To save development time, some parts of the test prototype are produced using $3 \mathrm{D}$ printing. The transplanting mechanism is installed on the frame, and the seedling pick-up device is shown in Figure 9. A working video of the transplanting mechanism is recorded using a high-speed camera (Phantom V5.1, U.S. Vision Research). The motion trajectory is determined by using the drawing method. It can be seen from the trajectory that the seedling pick-up needle is extended in the position of seedling pick-up and contracted in the position of planting; the actual trajectory is consistent with the theory trajectory.

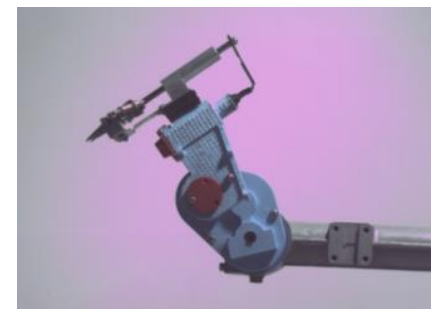

a. Seedling picking time

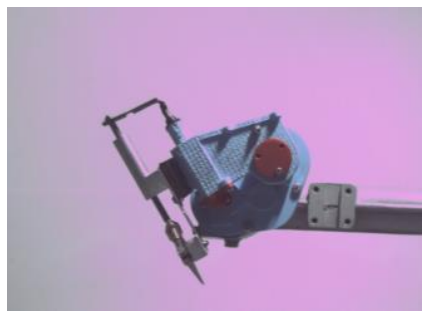

b. Seedling pushing time

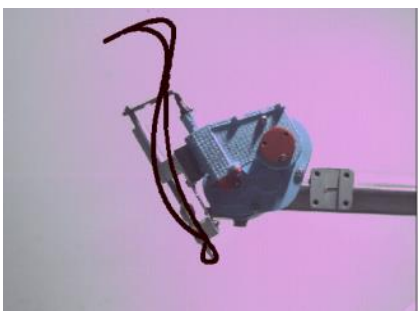

c. Motion track

Figure 9 The high-speed photography validation test

\subsection{Bench test}

To determine the optimal depth of seedling pick-up, the seedling pick-up test is conducted using different seedling pick-up depths. "Salvia Splendens" pot seedlings were selected in the experiment. Transplanting tests are completed through a built-up transplanting bench test, as shown in Figure 10. During the test, under the control of the motor, the conveyor rotates continuously at a uniform speed and moves in a direction far away from the mechanism.

Salvia splendens for the experiment is a dwarf variety and is randomly measured for 50 experimental seedlings with an average plant height of $71.26 \mathrm{~mm}$ and 5 leaves. The specifications of the tray are as follows: the number of points is $12 \times 6$, the caliber is $40 \times 40 \mathrm{~mm}$, and the tray depth is $40 \mathrm{~mm}$.

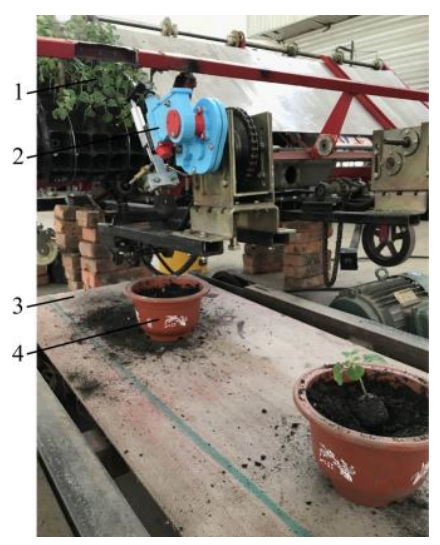

a. $45^{\circ}$ view of the test prototype

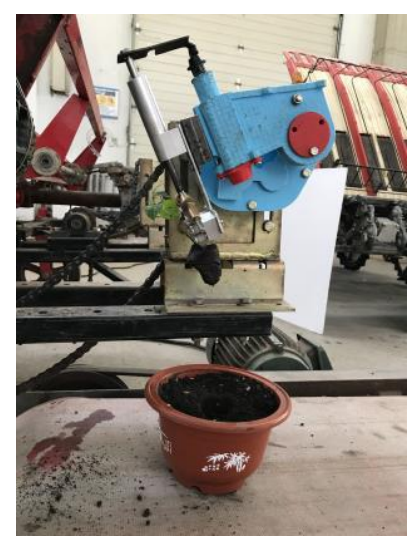

b. Front view of the test prototype
1. Salvia splendens seedlings $\quad 2$. Transplanting mechanism $\quad 3$. Conveyor belt 4. Flowerpot

Figure 10 Experimental bench test of the flowerpot seedling transplanting mechanism

It is found that the seedling pick-up effect is better when the seedling depth is $32-40 \mathrm{~mm}$, and the minimum seedling pick-up depth is determined to be $32 \mathrm{~mm}$. Because the tray depth is $40 \mathrm{~mm}$, the seedling pick-up needle may collide with the tray when the seedling pick-up depth is $40 \mathrm{~mm}$. To avoid the collision, the maximum seedling pick-up depth is $38 \mathrm{~mm}$. In summary, the range of the seedling pick-up depth is $32-38 \mathrm{~mm}$, and the three levels of selected seedling pick-up depth are $32 \mathrm{~mm}, 35 \mathrm{~mm}$, and $38 \mathrm{~mm}$. The seedling pick-up depth can be adjusted by adjusting the screw at the end of the seedling-pushing rod.

Because of the transplanting mechanism directly holding the base material by the seedling pick-up needle, after the seedling is successfully picked, the more the base material is wrapped in the root, the more favorable for the later survival of the seedling ${ }^{[18,19]}$. Therefore, the seedling pick-up success rate $Y_{1}$ and the base material integrity rate $Y_{2}$ are selected as the evaluation indexes of the test. The base material integrity rate $Y_{2}$ is evaluated by weighing as follows:

$$
Y=m_{1} / m_{2} \times 100 \%
$$

where, $m_{1}$ is the quality of the base material falling into the flowerpot, and $m_{2}$ is the quality of the base material before transplantation.

Each level is tested using 72 seedlings, and the integrity rate of the base material is calculated as the average of the test results at each level. The test results are shown in Table 1.

Table 1 Experimental results

\begin{tabular}{lccc}
\hline & \multicolumn{3}{c}{ Seedling depth/mm } \\
\cline { 2 - 4 } & 32 & 35 & 38 \\
\hline Success rate & $83.33 \%$ & $91.67 \%$ & $93.05 \%$ \\
Base material integrity rate & $72.91 \%$ & $81.14 . \%$ & $76.26 \%$ \\
Weighted value & $83.12 \%$ & $87.46 \%$ & $86.33 \%$ \\
\hline
\end{tabular}

According to the analysis of the test results, the success rate of seedling pick-up increases when the depth of the seedling picking increases; the success rate is lower when the seedling pick-up depth is $32 \mathrm{~mm}$. When the depth of the seedling pick-up is $38 \mathrm{~mm}$, the success rate of seedling pick-up is the highest. By analyzing the integrity of the base material, it can be seen that when the seedling 
pick-up depth is $32 \mathrm{~mm}$, the success rate of seedling pick-up is lower. When the seedling pick-up depth is $35 \mathrm{~mm}$, the success rate of the seedlings is the highest. The test results show that, when other conditions are the same, increasing the depth of the seedling pick-up can increase the success rate of seedling pick-up. To ensure that the transplanting mechanism does not interfere with the flowerpot, the smaller the distance between the flowerpot and the transplanting mechanism is, the higher the base material integrity rate. Selecting flower seedlings with better root stock can increase the base material integrity. To balance the success rate of the seedling pick-up and the rate of base material integrity, the weighted values of two indicators are used as the final evaluation indicators. According to the prophase test and related literature, after transplantation, a seedling with a base material integrity rate greater than $80 \%$ can survive. Thus, the success rate of seedling pick-up and base material integrity are calculated according to a weight of 6:4. The weighted value $Y_{3}$ is:

$$
Y_{3}=Y_{1} \times 60 \%+Y_{2} \times 40 \%
$$

When the seedling pick-up depth is $35 \mathrm{~mm}$, the weighted value is the highest, as shown in Table 1. Therefore, it is determined that the optimal seedling pick-up depth is $35 \mathrm{~mm}$.

A total of 72 seedlings are selected, and a seedling transplanting experiment is carried out. When the seedling pick-up depth is $35 \mathrm{~mm}, 66$ seedlings are successfully picked-up. The success rate of seedling pick-up is $91.67 \%$, and the subsequent growth is good. It is verified that a seedling pick-up depth of $35 \mathrm{~mm}$ can ensure successful transplantation.

\section{Conclusions}

(1) A flowerpot seedling transplanting mechanism has been invented. Different from the field pot seedling transplanting equipment, rotary-extensive-type flowerpot seedling transplanting mechanism is stationary with respect to the ground, the flower pot moves along with the conveying belt.

(2) A kinematic model of the mechanism is established. According to the visual optimization software Visual Basic 6.0, the human-computer interaction mode is adopted, the optimization design software of the transplanting mechanism is developed, a set of institutional parameters satisfying the requirements of pot-planting are obtained.

(3) The virtual simulation design of mechanism is carried out by using ADAMS software, and the test prototype is manufactured. Through a high-speed photography test, the trajectory change in the transplanting mechanism is analyzed. The results show that the mechanism's running attitude and trajectory is basically consistent with the theory.

(4) A bench test is used to determine the optimal seedling picking depth is $35 \mathrm{~mm}$, and the success rate of transplanting can reach $91.67 \%$.

\section{Acknowledgements}

This research was supported by the National Key Research and
Development Program of the 13th Five-year Plan (Grant No. 2017YFD070800).

\section{[References]}

[1] Li X M. 2019 year World Flower Conference held in Beijing. Land Greening, 2019; 9: 7. (in Chinese)

[2] Zhou B, Liu D M, Nie Y M. Effects of specialized controlled-release fertilizer on quality of herbaceous plug-seedling and growth of transplanting. Journal of Shandong Agricultural University: Natural Science Edition, 2010; 4: 50-53. (in Chinese)

[3] Gu S, Yang Y L, Zhang Y F. Development status of automated equipment systems for greenhouse potted flowers production in Netherlands. Transactions of the CSAE, 2012; 28(19): 1-8. (in Chinese)

[4] Brewer H L. Conceptual modeling automated seedling transfer from growing trays to hipping modules. Transactions of the ASAE, 1994; 37(4): 1043-1051.

[5] Choi W C, Kim D C, Yu H R. Development of a seedling pick-up device for vegetable transplanting. Transactions of the ASAE, 2002; 45(1): 13-19.

[6] Kutz L J, Craven J B. Evaluation of photo electric sensors for robotic transplanting. Applied Engineering in Agriculture, 1994; 10(1): 115-122.

[7] Liu J D, Cao W B, Tian D Y, Tang H Y, Zhao H Z. Kinematic analysis and experiment of planetary five-bar planting mechanism for zero-speed transplanting on mulch film. Int J Agric \& Biol Eng, 2016; 9(4): 84-91.

[8] Ye B L, Yi W M, Yu G H, Gao Y, Zhao X. Optimization design and test of rice plug seedling transplanting mechanism of planetary gear train with incomplete eccentric circular gear and non-circular gears. Int J Agric \& Biol Eng, 2017; 10(6): 43-55.

[9] Zhou M L, Hua Z Y, Wang J Y, Wang L, Zhao Y, Yin D Q. New type of transverse moving box mechanism for pot seedling transplanting machine. Int J Agric \& Biol Eng, 2018; 11(2): 70-75.

[10] Jin X, Li D Y, Ma H, Ji J T, Zhao K X, Pang J. Development of single row automatic transplanting device for potted vegetable seedlings. Int $\mathrm{J}$ Agric \& Biol Eng, 2018; 11(3): 67-75.

[11] Gao G H, Feng T X, Li F. Design and optimization of operating parameters for potted anthodium transplant manipulator. Transactions of the CSAE, 2014; 30(17): $34-42$. (in Chinese)

[12] Feng Q C, Wang X, Jiang K, Zhou J J, Zhang R, Ma W. Design and test of key parts on automatic transplanter for flower seedling. Transactions of the CSAE, 2013; 29(6): 21-27. ( in Chinese)

[13] Zhou M F, Xu J J, Tong J H, Yu G H, Zhao X, Xie J. Design and test of an automatic transplanting mechanism for flower cave seedling taking and transplanting. Transactions of the CSAE, 2018; 34(20): 44-51. (in Chinese)

[14] Zhou M L, Sun L, Du X Q, Zhao Y, Xin L. Optimal design and experiment of rice pot seedling transplanting mechanism with planetary bezier gears. Transactions of the ASABE, 2014; 57(6): 1537-1548.

[15] Zuo Y J, Yu X X, Li W G, Zhu H X, Ji H P. Kinematic optimization of transplanting mechanism with B-Spline curve gear for rice pot seedling based on Matlab. Applied Mechanics and Materials, 2014; 624: 181-186.

[16] Zhao Y, Zhou M L, Yin D Q, Zhang S. Rotary flower potted plant. Chinese Patent No. CN201610102591.2, 2016-02-17.

[17] Zhao Y, Zhao X, Zhang W W, Dai L. Modern design theory and method of rice transplanter. Transactions of the CSAM, 2011; 42(3): 79-83. (in Chinese)

[18] Hu M J, Yin W Q. Experimental research on the deformed sliding needle pick-up device for plug seedlings. Acta Agriculturae Zhejiangensis, 2011; 23(1): 154-158. (in Chinese)

[19] Wang Y Y, Yu Y H. Experiment and analysis of impact factors for soil matrix intact rate of manipulator for picking-up plug seedlings. Transactions of the CSAE, 2015; 31(14): 21-27.( in Chinese) 